\title{
Konsens im Allgemeinen Verwaltungsrecht und in der Demokratietheorie
}

Untersuchungen zur Phänomenologie gruppenpluraler Konsensverwaltung unter besonderer Berücksichtigung des Sozialrechts als Referenzgebiet

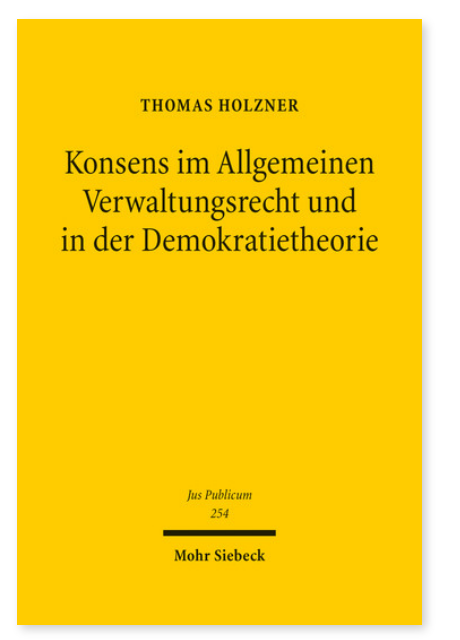

2016. XXXII, 652 Seiten. JusPubl 254

ISBN 978-3-16-154338-8

DOI 10.1628/978-3-16-154338-8

eBook PDF 144,00€

ISBN 978-3-16-154330-2

Leinen $144,00 €$
Thomas Holzner untersucht konsensuale Handlungs- und Organisationsformen sowie den Einbezug Privater in diese auf ihre Gemeinsamkeiten. Dabei werden nicht nur das Sozialrecht, sondern auch andere Rechtsgebiete, wie z.B. das Hochschul-, Wirtschafts-, Lebensmittel- und Medienrecht als Referenzgebiete herangezogen. Der Autor versucht, diese mit der Kategorisierung als gruppenplurale Konsensverwaltung dogmatisch zu erfassen und in das System des Allgemeinen Verwaltungsrechts zu integrieren. Gleichzeitig stellt er eine Theorie zur demokratischen Legitimation dieser Phänomene vor, die es unter Fortbildung des klassischen Legitimationsmodells ermöglicht, die demokratische Legitimation von Organisationsformen wie dem Gemeinsamen Bundesausschuss, aber auch z.B. den öffentlich-rechtlichen Rundfunkanstalten, der Filmförderungsanstalt oder der Lebensmittelbuch- und der Gendiagnostik-Kommission zu begründen.

Thomas Holzner Geboren 1975; Studium der Rechtswissenschaften und der Politikwissenschaften; Tätigkeit als Rechtsanwalt; 2009 Promotion; Wissenschaftlicher Mitarbeiter/Akademischer Rat an der Universität Bayreuth; 2015 Habilitation, venia legendi für Öffentliches Recht, Sozialrecht, Rechts- und Verfassungsgeschichte; SoSe 2015 Vertretung der Professur für Öffentliches Recht und Europarecht an der Universität Hannover.
Jetzt bestellen:

https://mohrsiebeck.com/buch/konsens-im-allgemeinen-verwaltungsrecht-und-in-der-demokratietheorie-9783161543388? no_cache=1

order@mohrsiebeck.com

Telefon: +49 (0)7071-923-17

Telefax: +49(0)7071-51104 